\title{
MEET MIRAT \\ LEGAL REASONING FRAGMENTED INTO \\ LEARNABLE CHUNKS
}

\author{
JOHN H WADE*
}

The ubiquitous aim of legal education is for students to learn how "to think like lawyers". It has often been noted that this is a frustratingly imprecise educational goal. ${ }^{1}$ Nevertheless, some students stumble upon, or methodically work out, an analytical style of thought, writing and speaking which is rewarded at law school by nods, ticks, high grades, scholarships and envy. "Thinking like a lawyer" is also a depressingly inaccurate goal as we know very little about how the many sub-cultures of lawyers think, speak or behave. ${ }^{2}$

In the writer's limited experience, most lawyers think, speak and write in layers of styles and street cunning which often obscure the foundational analytical style (rightly) emphasised in foundational legal learning. ${ }^{3}$

What is this analytical style of expression that is a part of the behaviour of many lawyers? Certainly it is a deviant style as most lawyers tend to stand our so quickly in a meeting (and not only due to their confidence, motor vehicles and dress patterns). In colloquial terms lawyers' contributions to any discussion tend to be exact, argumentative, insightful, reserved, balanced, evasive, obscurantist, precise and uncommitted. ${ }^{4}$ Can the learning process at law school towards these much admired, sometimes despised qualities, be demystified? Behaviourist or task analysis approaches to education are creeping into law schools mainly via the current interest in learning "skills".

Here is one method of describing the analytical aspect of "thinking like a lawyer" which has proved to many law students to 
be:

- easy to remember

- able to be used at different levels of sophistication

- capable of use in every area of law

- useful to define a personal or group educational goal

- a reasonably precise method for a student to measure higher performance in any written/spoken exercise

- a helpful method for teachers to model in chunks

- a satisfying method for marking written or spoken analytical exercises as strengths and weaknesses of each stage can be so precisely identified.

This breakdown of the ubiquitous "thinking like a lawyer" is described by the acronym MIRAT. Its use has been foreshadowed in various forms in other journal articles. ${ }^{5}$

The letters in "MIRAT" stand for:

$\begin{array}{lll}\mathrm{M} & - & \text { Material facts - present or absent } \\ \mathrm{I} & - & \text { Issues of law and “policy” } \\ \mathrm{R} & - & \text { Rules and Resources } \\ \mathrm{A} & - & \text { Arguments (or Application) } \\ \mathrm{T} & - & \text { Tentative Conclusion }\end{array}$

It should be emphasised the MIRAT analysis is flexible and has been modified by some teachers by adding extra concepts. Additionally, even though each of the five concepts can be modelled in isolation, they inevitably interact (particularly the first three). For example, it is obvious that as research unearths more "rules", which leads to identification of new issues, questions about missing material facts, and a quota of fresh arguments. That is, it is an identifiable skill itself to move "to and fro" between the first three concepts thereby expanding and refining material facts, issues and rules.

\section{MATERIAL FACTS}

The first task and skill under this model is the identification of "material” or "relevant" facts. While developing this skill, discussion and research can very profitably "wander" into mammoth topics such as cultural differences of relevance, client perceptions of relevance, professional control of information, interviewing technique, evidentiary methods of establishing historic "facts", the cost of fact-collection and the elusive nature of facts. ${ }^{6}$ 
Such an exciting agenda of "side-issues", "incidental" topics and "underlying" questions may mean that the students of this first skill either become bogged down or enraptured. A teacher needs to have clear goals and time agenda if (s)he wants students to see, practise and receive feedback on each part of the MIRAT model.

A "material" fact can be described as a fact which is of vital importance to a line of deductive reasoning in order to solve a problem or to give helpful advice on a range of options in response to a particular or social problem. A teacher can usefully model this concept by identifying three categories of facts:

- clearly material facts, eg "Bill pulled the trigger of the gun"; "the net income of the firm decreased by 40\%".

- clearly immaterial facts, eg "Jane has freckles"; "David once travelled to San Francisco”.

- facts which may be material once extra rules, policies, facts and issues are identified, eg "Jane has freckles"; "David once travelled to San Francisco".

The majority of law school tutorial, mooting and examination questions present a packaged (and often sterilised) version of facts. However, in the writer's experience, a question such as "Are there any additional facts which you would like to know in order to give preliminary advice?” asked to a whole class or in buzz groups invariably produces an astounding array of requests for missing information. A running list of desired extra facts can be recorded on a whiteboard as problem-solving ferments and matures in a group or class.

Students should not be allowed to escape the question "What material facts are missing?" by pleading "rule" ignorance. The beginnings of material facts can be unearthed by the question "From your life experience, what extra facts might be relevant to the final outcome of this problem/dispute?”.

Students tend to disagree vehemently on what is relevant or material when analysing any micro or macro "problem". These disagreements can be developed constructively by a teacher who pursues the following process:

- “Can you elaborate upon why this is a material fact for you?"

- Record on a whiteboard each underlying "rule", policy or value which makes a fact relevant for each student, eg male judges are sympathetic towards pretty women; politicians are influenced by 
the amount of previous publicity given to sporting injuries; the rule in the textbook states that insurance coverage is not relevant to tortious liability; mine workers should no longer be exploited by multinational corporations; Judge Smith hates homosexuals.

- "What are the relevant facts if Bill's rules, values and policies are applied? What are the relevant facts if Mary's rules, values and policies are applied?"

- What if the rule to be applied is the following taken from this statute and case? What are the material facts we need?

\section{ISSUES}

Issue-spotting is a favourite and important game learned by most law students. Law teachers have often been heard to say "It is more important to ask the right questions then to find the right answers".

Issues are often stated as rhetorical questions "Was there a contractual offer on 3 March?” Is there a duty of care owed to a trespasser?" "Was the bank liable to a fine under S 14 of the Banking Act for failing to make full disclosure?”

The issues or questions surrounding any particular social debate or micro problem solving exercise, can themselves be stated at a "macro" or "micro" level. For example, arising out of a motor car accident, the issue could be "At law, how should the cost arising out of physical injury be distributed in a modern industrialised society?" or more narrowly, "what is the meaning of 'unsafe tyres' as specified in s 4 of the Motor Registration Act?" Students can be asked, without abandoning their larger issues, to break them into multiple issues which are more manageable for a building block analysis. Like material facts, issues emerge gradually. They arise initially from experience, first impressions or gut reactions, and then in more detail as legal research progresses. As any issue is identified, the question can be asked "How did you decide that was an issue?” Inevitably, the accurate statement of legal rules inevitably intertwines with the task of identifying a complete list of issues.

\section{RULES (RESEARCH AND RESOURCES)}

The "R" in MIRAT represents "rules" but can also refer to 
"research” and "resources”. Law students are sometimes too readily intimidated into using books as their only research resource. The skills of interviewing the right person at the right time should also be emphasised. As foreshadowed when discussing material facts and issues, this third step involves attempting to identify what rules, policies and values will be applied to a particular macro or micro problem. Developing this allegedly narrow library skill leads quickly into jurisprudential debates - for example, how do you know what rules will apply until after the issue is resolved? Why read case-law or book-law when street law or nebulous "commercial factors" are usually better predictors? Why restrict research to the "law" library?

Nevertheless, despite the importance of these jurisprudential debates, the foundational skill being learned should not be lost or derailed (at least at an early stage of a law student's learning). That is, it is clear that all lawyers must acquire the basic skills of locating current case and statutory rules and expressing these accurately. Students can be brought back to this task repetitively by a series of questions:

- "Please tell me, according to the books, what rule applies to this particular issue?”

- "How did you locate that rule?"

- "What alternative versions to that rule did you discover?"

These questions enable a constant pooling of information about book, computer and people resources. Additionally, skills in the precise expression of a variety of versions of rules at different levels of generality are repetitively practised. Once again "narrow" skill development leads readily to the discussion of evergreen questions such as - at what level of generality should the rule/ratio decidendi/proposition emerging from a case be stated? Why do judges write judgments?

Going beyond "book" rules, some students will be particularly attracted to street law, the law in action, trial judge law, procedure, tactics, the "current political climate" or rampant cynicism as the governing, or at least relevant, rules, policies and values applicable to a particular issue. These rules should be assiduously pursued, but never thereby losing the basic skill of book law location and articulation.

This sequence of questions may assist to put some precision and 
methodology into the identification of rules in action:

- "What are the rules/values/policies which you think may influence the outcome of this issue?"

- "What resources or experts are accessible to us (at what cost?) to identify the current version, weight and status of this rule/value/ policy?"

- "What alternative versions of this rule/policy/value have you been able to locate? (Set these out precisely.)"

This can lead readily to important discussions of access to distant or expensive experts; the ephemeral nature of expertise; the notable difference of opinions between experts; the influence of payment upon expert opinion.

The MIRAT model moves on from "Rule" to "Argument" or “Application”.

\section{ARGUMENTS — PRO AND CON (OR APPLICATION)}

Initially, most law students yearn for the certainty of a clear answer. They tend to leap quickly from facts, issues or rules to a conclusion. Repetitively they need to be taken a step back and asked to develop arguments on both sides of the issue being dealt with. For every punch, there is a counter punch; for every move, there is an orthodox counter move. These games can be systematised and thereby demystified' It is the writer's experience that students often develop creative arguments and counterarguments based on their own life experiences or perceptions of "policy". Educationally, there is no such thing as a "wrong" or "foolish argument. Later in a lawyer's career, culturally inappropriate arguments will be conditioned out of him/her by public ridicule, gossip, snicker, loss of clients and social excommunication. Such methods of creating conformity, however, hardly foster the inquisitive spirits which are so precious in an educational institution. Every convincing or less-than-convincing argument can be met with a proposition such as - "well, how would you respond to your own argument?” (“A brilliant argument - I give up” is not a culturally acceptable response at this stage).

When a reasonable quota of moves and counter moves have been identified, articulated, refined and written out (if possible visible to the whole class), the process moves on to its fifth step namely attempting to identify a conclusion to the particular issue 
being dealt with.

\section{TENTATIVE CONCLUSION — OR CONCLUSION}

The writer prefers the adjective "tentative" to the unqualified "conclusion”. This is done again to counteract student yearning to confidently reach strong conclusions on each issue discussed. No doubt confident and unqualified conclusions are justified where the weight of arguments towards such conclusions are overwhelming. In such cases, the acronym MIRAC is more appropriate than MIRAT to describe the reasoning process.

Students need to practise various styles of expression in order to avoid misleading with an over-confident, under-confident or premature conclusion. For example, "It is probable/very probable/virtually certain that the outcome of this issue will be _ _ . "This is because _ _ . " Or "It is uncertain what the outcome of this issue will be as we are missing three key facts, namely _ _ If these missing facts were found to be ${ }_{-}{ }_{-}$then ${ }_{-}{ }_{-}$." Or "The opposite conclusion would be likely to follow if:

(i) a rule is changed, eg a case overruled; or

(ii) extra facts showing that are established.”

Having reached a confident or tentative conclusion on one issue, the whole process is repeated by moving on to the next issue. Some terminology needs to be developed in order to oil the transition. For example, "Assuming that this conclusion is accepted, then the next issue is _ _ _." Or "If this conclusion is ultimately not the one adopted by a judge, the next issue is _ _. ." Reasoning then moves again through the four IRAT steps.

Students are often daunted by the multiplying lines of endeavour which necessarily flow once it is acknowledged that any issue has more than one possible conclusion. How many permutations need to be pursued in order to analyse a problem "properly"? Some relief can be given to anxious students if the teacher repetitively models at the end of a class which route of possible/probable conclusions (s)he would have explained in detail at least within a limited time constraint. At the law school stage of education, the development of reasoning and process skills is far more important than discovering the probably right answer path through a sequence of issues. 


\section{ILLUSTRATION OF THE APPLICATION OF MIRAT}

Consider a "simple" fact situation which may be presented to a first year law student, a post-graduate consumer protection $\mathrm{PhD}$ student or a practising lawyer for advice.

"Jane, an architect and a frequent customer of the Bargain Lines Supermarket Pty Ltd, picked a bottle of cleaning fluid off the shelf in the supermarket. The bottle was marked "\$3.95". As she approached the check-out counter of the supermarket, the bottle of fluid, resting in her trolley exploded. A fragment of glass destroyed Jane's left eye. Does Jane have any legal remedies?”

The MIRAT analysis can provide a useful teaching and analytical tool to approach this event. What follows is an edited version of conversations between a teacher $(\mathrm{T})$ and students in both lecturers and tutorials when an analogous problem has been discussed.

\section{MATERIAL FACTS — PRESENT OR ABSENT}

$\mathrm{T}$

Michelle

$\mathrm{T}$

Michelle "The material facts are set out in the written problem.”

Bob "Can I make a comment. I think that these facts are unrealistic. Virtually every fact given is material. In real life Jane's story would be much more convoluted and emotional. I suppose that the fact that she was a frequent customer is not material.” (Discussion of artificial packaging of "facts" for educational purposes follows).

Mark "I disagree. There are too many frills in these facts. The only material facts in this example are that a customer was injured by an exploding article on sale in a supermarket.” 
Mary “Look, I can't answer the materiality question until I know the applicable legal rules. The Boots Cash Chemist ${ }^{8}$ case found that goods on the shelves of a self-service store do not amount to contractual offers - so the fact that the bottle had a price on it is probably irrelevant."

Bob "That's not the ratio of the Boots case. That's a statutory interpretation case; everything else is only obiter."

"OK before discussing in detail which correct legal rules to apply to this problem, can I ask you some questions? Would it have been material if Jane was wearing a blue shirt?”

Chorus "No!” (and assorted headshaking)

$\mathrm{T}$

"Is it relevant that Jane was

- an architect?

- a woman?

Is it relevant to know who has insurance? Whether there have been other accidents at the supermarket, or with these bottles of cleaning fluid?”

(Discussion proceeds).

Bob "You're leading us into the wilderness here. How many facts can we assume? For how long should we discuss possible fact which are not in the question? How much time is given in exams?” etc etc. (Discussion of exam writing technique and professional advice-giving technique follows).

\section{ISSUES}

$\mathrm{T}$

"We will have to come back to consider any further missing material facts we decide are needed. Using the basic facts that are before you, what are the issues that arise?”

Peter "There are five issues. Is a label on a bottle in a supermarket a contractual offer? If so, has Jane accepted the offer? If so, is there an implied term that the bottle is reasonably safe? If so, what amount of contractual damages are payable by the supermarket for loss of an eye of a female architect?" 
Joanne "There's a broader question of how should compensation for physical injury be distributed in modern industrial societies.”

Bill “That’s not law?” (Discussion follows of macro and micro issues).

Mark "What about the duty of care of the manufacturer of the cleaning fluid and of the bottle? Is there a duty of care upon the person who filled and sealed the bottle? That's another missing material fact - do we know why the bottle exploded? Did Jane shake it?”

Judy "Is there any consumer protection legislation which can apply to Jane?” etc etc.

$\mathrm{T}$

"Having identified all these issues on the board, in which order will you attempt to address them?"

\section{RULES}

T "Can you quote me precisely any legal rule which potentially applies to each of these issues?”

Mark

“...............”,

$\mathrm{T}$

"Where did the rule come from?"

Mark

“...............”

T "How did you find it?"

Mark “ “..............”

$\mathrm{T}$

"What rule versions have others discovered?"

Michelle,

Bob,

David

$\mathrm{T}$

"Which of these different rule versions should we begin to apply? Why that particular version?’

$\mathrm{T}$

"Who might you have asked, and where might you have looked in order to discover other rules or policies potentially applicable to this problem?” (T gives a list of illustrations of people and literature).

"Having identified the rule versions we propose to apply, 
let us retreat for a moment. Have these "rules" raised any more present or missing material facts? Have the rules raised any more issues than we have already listed?”

\section{ARGUMENTS PRO AND CON (OR APPLICATION)}

$\mathrm{T}$

Mary

$\mathrm{T}$

$\mathrm{T}$

Bob

$\mathrm{T}$

$\mathrm{T}$

Bill

$\mathrm{T}$

Michelle "And if I responded to your response with this is your next move?"9 can you assemble that a labelled bottle on a supermarket shelf amounts to an offer?”

"Well, clearly a bottle label is not an offer."

"Hang on, Mary, we missed a step. I don't want a conclusion just yet. I want the arguments in favour of an offer.”

"OK. Now what are the counter arguments to each of Mary's arguments?”

"It's ridiculous to argue such an impossible position ... “

"Excuse me Bill, can I just interrupt to give you some advice on language. Legal culture requires the use of dispassionate counterarguments and the avoidance of denigrating language.” (T. illustrates by repeating Bill's first argument ... .”)

"Why do you think lawyers speak this way?" (Discussion of the function of etiquette, hypocrisy and dispassion follows).

"Bill, can you repeat your counter arguments in a defused fashion?”

"With difficulty."

"Apart from the arguments we have assembled so far, how would you respond if I put the following argument to you on the first issue?”

"Applying this legal rule to this first issue, what arguments response with exaggerated politeness "I submit that Mary's what

\section{TENTATIVE CONCLUSION}


counter-punches (recorded on the board) - which group of arguments is most persuasive to each of you? I want a vote (eg. by show of hands).” (Discussion of unpredictability of judicial decisions follows).

Michael "My conclusion on this first issue is not 'tentative'. The standing bottle is definitely not a contractual offer."

T "What will you say to a judge who does not agree with our definite conclusion?”

Michael "I'd appeal." (Discussion of the eggs in one basket principle and the cost of appeal).

Judy "My conclusion is tentative - it is not an offer but I would want to do some more research to see if any cases have distinguished the Boots Cash Chemist case.

T So would you ask Jane whether she can afford to pay for more legal research into the history and current state of the rules?”

Judy "I suppose so.” (Discussion of cost of different grades of legal advice).

Bob "I'd have to reserve any strong conclusion on that first issue until we had some more facts."

$\mathrm{T} \quad$ "Can you specify exactly what factual questions you want answers to Bob?"

Bob “..............”

$\mathrm{T} \quad$ "OK Bob, please repeat your conclusion qualified by those two factual clarifications.”

Bob

“...............”

T "How do we move on from the first to the second issue?"

Mary "On the assumption that the labelled bottle is not an offer, the next issue is. .... “

\section{CONCLUSION}

Broadly stated educational goals such as "thinking like a lawyer” have often been the cause of sloppy course preparation and execution, not to mention student frustration. By way of contrast, the MIRAT framework of analysis provides simple, structured and 
measurable smaller goals. MIRAT may not be helpful to all styles of student learning, but it has been explained, modelled and tested by the writer for a number of years with enthusiastic student (and practitioner) response.

\section{POST-SCRIPT: MEET CAGONARM}

At risk of drowning readers in a sea of acronyms, here is another! This is a form of task analysis which has arisen from frequent observation of student confusion when addressing "policy" issues, and of intuitive or learned behaviour by various members of law reform commissions. Presumably somewhere a political scientist has developed these steps into a sophisticated model or scaffolding.

If MIRAT provides a framework or acronym to address micro problems, can a framework be devised to address "macro", policy and social issues? For example -

- How can the post-marriage breakdown poverty of custodial parents be alleviated?

- What steps can be taken to address the apparent exploitative nature of leases in many shopping malls?

- To what extent is the corporate veil appropriate in (Australian) society?

- What controls should exist upon the granting of credit?

- What immigration policies should be in place in Australian society in the short and long term?

Law reformers often develop a step-by-step approach intuitively and by experience when addressing "social” issues. These steps can be identified, modelled and practised. Each step involves a range of sub-skills, attitudes, knowledge which can also be identified, modelled and practised. The acronym CAGONARM can be applied to identify the orthodox steps used (in the writer's experience) by many law reform commissions (and presumably by many other “planning” bodies).

The aspirations of some law schools and law courses to engage in social planning necessarily requires more than exhortation. ${ }^{10} \mathrm{~A}$ considerable investment of time and resources needs to be made into studying and systematising social planning methods, and then into the methods of teaching such methods.

The letters in CAGONARM stand for: 


\section{Current situation — what is it?}

Alleged problems and deficiencies with the current situation

Goals - what are the desirable features of a "good system?

Options - the field of choice for change

Necessary action to achieve each possible option

Advantages and disadvantages of each option

Recommending the least detrimental alternative

Monitoring and measuring the effects of the reform once it is implemented on the basis of predefined criteria of "success".

This acronym will be discussed further in a subsequent note.

* School of Law, Bond University.

(C) 1991. (1990-91) 2 Legal Educ Review 283.

1 RF Mager, Preparing Instructional Objectives 2d ed (Belmont, California: David S Lake, 1984) American Bar Foundation, Law Schools and Professional Education (Chicago: ABA Press, 1980).

2 Eg, JH Wade, The Behaviour of Family Lawyers and the Implications for Legal Education (1989) Legal Educ Review 165 note 1.

3 See S Gillers, Great Expectations: Conceptions of Lawyers at the Angle of Entry (1983) J Legal Educ 662.

$4 \quad$ Id.

5 Eg, HFM Gombag et al, On Solving Legal Problems (1975) 27 J Legal Educ 168; PW Gross, On Law School Training in Analytic Skill (1973) $25 \mathrm{~J} \mathrm{Legal}$ Educ 261. The writer presumes that there are many articles which more directly refer to and develop the MIRAT concept.

6 DA Binder and P Bergman, Fact Investigation - From Hypothesis to Proof (St Paul: West, 1984); W Twining, Taking Facts Seriously (1984) 34 J Legal Educ 22.

7 Eg RW Gordon, Critical Legal Studies as a Teaching Method (1989) 1 Legal Educ Rev 59 at 77-80.

8 Pharmaceutical Society of Great Britain \& Boots Cash Chemists (Southern) Ltd [1953] 1 QB 401.

$9 \quad$ It is a helpful exercise to attempt to systematise the orthodox moves and counter moves. Eg, see K Llewellyn, Remarks on the Theory of Appellate Decision and the Rules or Canons About How Statutes are to be Construed (1949-50) 3 Vanderbilt LR 395; Gordon, supra note 7. In statutory interpretation particularly, there are predictable moves in argument games concerning the meaning of any word, eg is a water pistol a "gun"?

YES

(i) Broad literal meaning

(ii) Not so absurd in these

(iii) Alleged historical purpose and context of words.
NO

versus Possible absurd consequences

versus Narrow literal meaning circumstances

versus Different alleged historical purpose and context of words

10 For example - Law and Learning - Report to The Social Sciences and Humanities Research Council of Canada by the Consultatia Group on Research and Education in Law (1983) (the Arthurs' Report); HD Lasswell and MS McDougal, Legal Education and Public Policy: Professional Training in the Public Interest (1943) 52 Yale L J 203. 